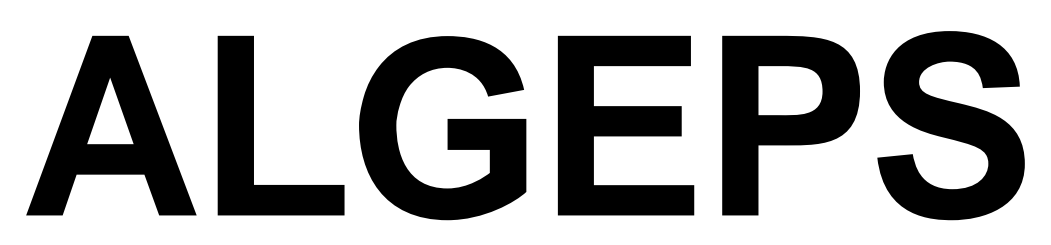

REVISTA DE GEOLOGIA, SÈRIE B no 587 - Abril del 2012

ISSN $1132-7014$

D.L.B. 28.178 - 92

12 pàgines

RECORRIDO DESDE NAVAL (SOMONTANO) A ABIZANDA, MEDIANO Y A L'AINSA, A TRAVÉS DEL PATRIMONIO GEOLÓGICO Y MINERO DE LA COMARCA DEL SOBRARBE

Josep M. Mata-Perelló

Aquest recorregut va ésser experimentat amb docents el dia 10 DE JUNY DEL 2010 


\section{RECORRIDO DESDE NAVAL (SOMONTANO) A ABIZANDA, MEDIANO Y A L'AINSA, A TRAVÉS DEL PATRIMONIO GEOLÓGICO Y MINERO DE LA COMARCA DEL SOBRARBE}

\section{ADVERTENCIAS PREVIAS}

Como en otros recorridos de RECONOCIMIENTO GEOLÓGICO (o de RECONOCIMIENTO GEOLÓGICO Y MINERO), el recorrido se compondrá de diversas PARADAS.

Por otra parte, habrá que tener en cuenta, en todo momento, (especialmente antes de empezar los recorridos de los diferentes tramos), el estado de los caminos y carreteras, por donde transitará el recorrido.

Finalmente, como ya hacemos en otros recorridos similares, queremos decir que hace falta tener un cuidado muy especial en el respeto a la naturaleza, a lo largo de todo el recorrido del itinerario, y también fuera de él.

\section{BREVE INTRODUCCIÓN GEOLÓGICA}

Todo el recorrido de este itinerario, se desarrollará por distintas zonas ocupadas por el Sistema Pirenaico (o simplemente por los Pirineos). Concretamente, en todo el recorrido se circulará por el denominado Surpirineo Central.

Así, el recorrido se iniciará en las cercanías de Naval, dentro del denominado Surpirineo Central, por los denominados Pirineos Meridionales (también a menudo conocidos como Prepirineo Meridional). Luego, siempre dentro de esta unidad geológica, se irá circulando hasta Abizanda y posteriormente hasta l'Ainsa, en donde finalizará el recorrido.

\section{BREVE INTRODUCCIÓN GEOGRÁFICA}

El recorrido del presente itinerario se efectuará casi exclusivamente por una comarca aragonesa, por la del Sobrarbe. No obstante, ase iniciará en la del Somontano, concretamente en Naval. Luego, a partir de ahí, el recorrido se dirigirá hacía Abizanda y posteriormente a Mediano y a l’Ainsa, en donde finalizará.

Por otro lado, la totalidad del recorrido transitará dentro de la cuenca del río Cinca, aunque los primeros tramos los efectuará por el valle de uno de sus afluentes, por 
el río Llastre. El resto del recorrido, desde Abizanda hasta l’Ainsa, lo realizará por el margen derecho (en sentido descendente) del río Cinca.

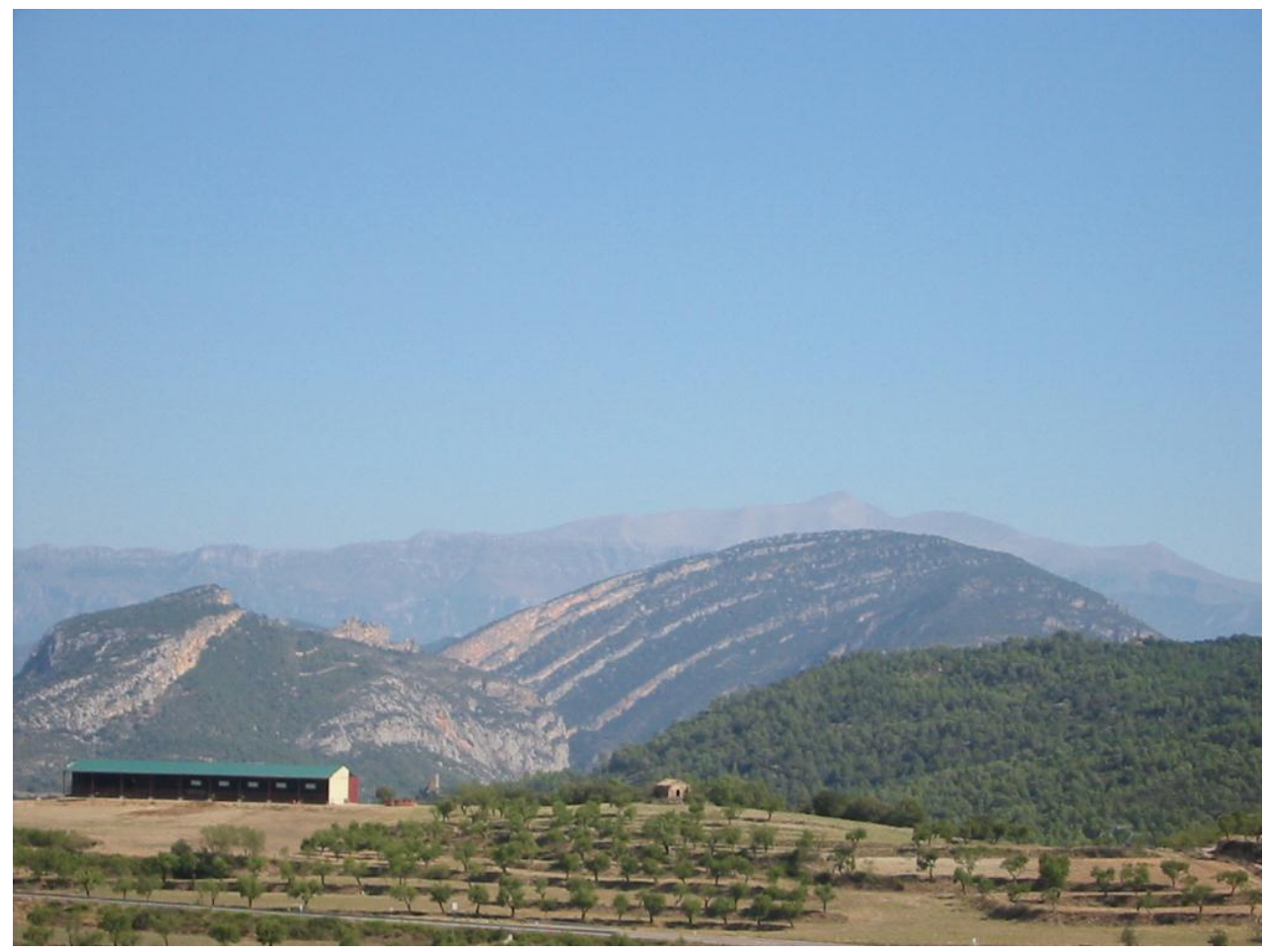

El Anticlinal de Santa Bárbara, desde Abizanda

\section{OBJETIVOS GENERALES DE ESTE ITINERARIO}

En este itinerario, los objetivos generales que se han de conseguir, se pueden concretar en los siguientes aspectos:

1.- Estudio y reconocimiento de los materiales mesozoicos y cenozoicos situados en el Surpirineo Central. Estos materiales los iremos encontrando a lo largo de todo el recorrido del itinerario.

2.- Estudio y reconocimiento de las estructuras del Surpirineo Central, a lo largo de todo el recorrido del itinerario.

3.- Visión de algunas de las antiguas explotaciones encontradas a lo largo del recorrido del itinerario.

4.- Visión de los diferentes lugares directamente relacionados con el Patrimonio Geológico que iremos encontrando a lo largo del recorrido de este itinerario. Dentro de él cabe mencionar el relacionado con el Anticlinal de Santa Bárbara.

5.- Visión de los diferentes lugares directamente relacionados con el Patrimonio Minero que veremos a lo largo del recorrido de este itinerario. Dentro de él cabe mencionar el relacionado con las Salinas de Naval (Somontano), entre otros lugares, 


\section{ANTECEDENTES BIBLIOGRÁFICOS}

En relación con este itinerario, no conocemos ningún antecedente, de otro autor relativo a otro itinerario que discurra por este lugar. Hay, no obstante algunos antecedentes nuestros (MATA-PERELLÓ 1998, 2005 y 2007).

Por otra parte, haremos mención de algunos trabajos, de carácter geológico generalista, que corresponden a los trabajos del IGME (1972, 1974 y 1975), relativos al Mapa Geológico de España (a Escala 1.200.000), al Mapa Metalogenético de España y al Mapa de Rocas Industriales de España.

Con respecto a las mineralizaciones que iremos encontrando, mencionaremos los trabajos de: CALVO et altri (1988); MAESTRE (1845); así como nuestros trabajos: MATA-PERELLÓ (1987 y 1992).

También mencionaremos el trabajo de PRAMES (2005) dedicado a la comarca del Jiloca. Así como el del GOBIERNO DE ARAGÓN (2001), dedicado a los Puntos de Interés Geológico de Aragón.

Finalmente, diremos que todos estos trabajos (así como otros que ahora no hemos aludido), figurarán mencionados, por orden alfabético, en el apartado dedicado a las REFERENCIAS BIBLIOGRÁFICAS.

\section{RECORRIDO DEL ITINERARIO}

Este recorrido se iniciará en las inmediaciones de la población de Naval, por donde se efectuará la primera parada del itinerario. Luego, el recorrido se dirigirá hacía la población de Abizanda, en donde se realizaran varias paradas. En este tramo se pasará de la comarca del Somontano a la del Sobrarbe, que ya no se abandonará.

Tras ello, por la carretera autonómica que conduce a l'Ainsa, se pasará por las cercanías de Escanilla, hasta llegar al Mesón de Ligüerri, desde donde se hará una hijuela hasta el puente sobre el río cinca. Tras regresar a la carretera autonómica, el recorrido seguirá hacía Mediano, iniciando luego una hijuela hasta la Pardina, en donde se hará una parada.

Tras regresar a la carretera autonómica, las inmediaciones de Camporrotuno. Posteriormente, el recorrido se dirigirá hacía Morillo de Tou y hacía l'Ainsa, donde finalizará, tras efectuar algunas paradas.

\section{DESCRIPCIÓN DEL ITINERARIO}

Como de costumbre, haremos una serio de PARADAS (o ESTACIONES), en donde se realizaran diversas explicaciones en torno a las características del lugar en donde se halla la PARADA. 
Por otra parte, en ellas haremos mención del término municipal dónde se encuentran, así como del número del "Mapa Topográfico Nacional (a escala 1:50.000, que indicaremos entre paréntesis. Así, ahora (en este recorrido) utilizaremos solamente las hojas: 211 (o de Boltaña), 212 (o de Campo y 250 (o de Graus).

Así, la relación ordenada de las paradas que constituyen el recorrido de este itinerario, es la siguiente:

PARADA 1. SALINAS DE PISA, (término municipal de Naval, comarca del Somontano). (Hoja 250).

El recorrido del presente itinerario, cabe realizarlo en este lugar. Estas salinas se encuentran a la entrada de Naval, viniendo desde lo Grado. Se hallan, a menos de $1 \mathrm{Km}$, aproximadamente de la población.

Este lugar se halla situado en los Pirineos; concretamente en el denominado Surpirineo Central. Así, en este lugar hay afloramientos de los materiales triásicos del Keuper, con presencia de yesos y de arcillas. Entre los yesos se encuentran indicios de HALITA.

Precisamente, en este lugar hubo unas importantes salinas. En ellas se aprovechaba la HALITA (la sal común) procedente de aguas saladas esparcidas por las eras. Estas aguas habían circulado entre los materiales del Keuper, disolviendo la sal.

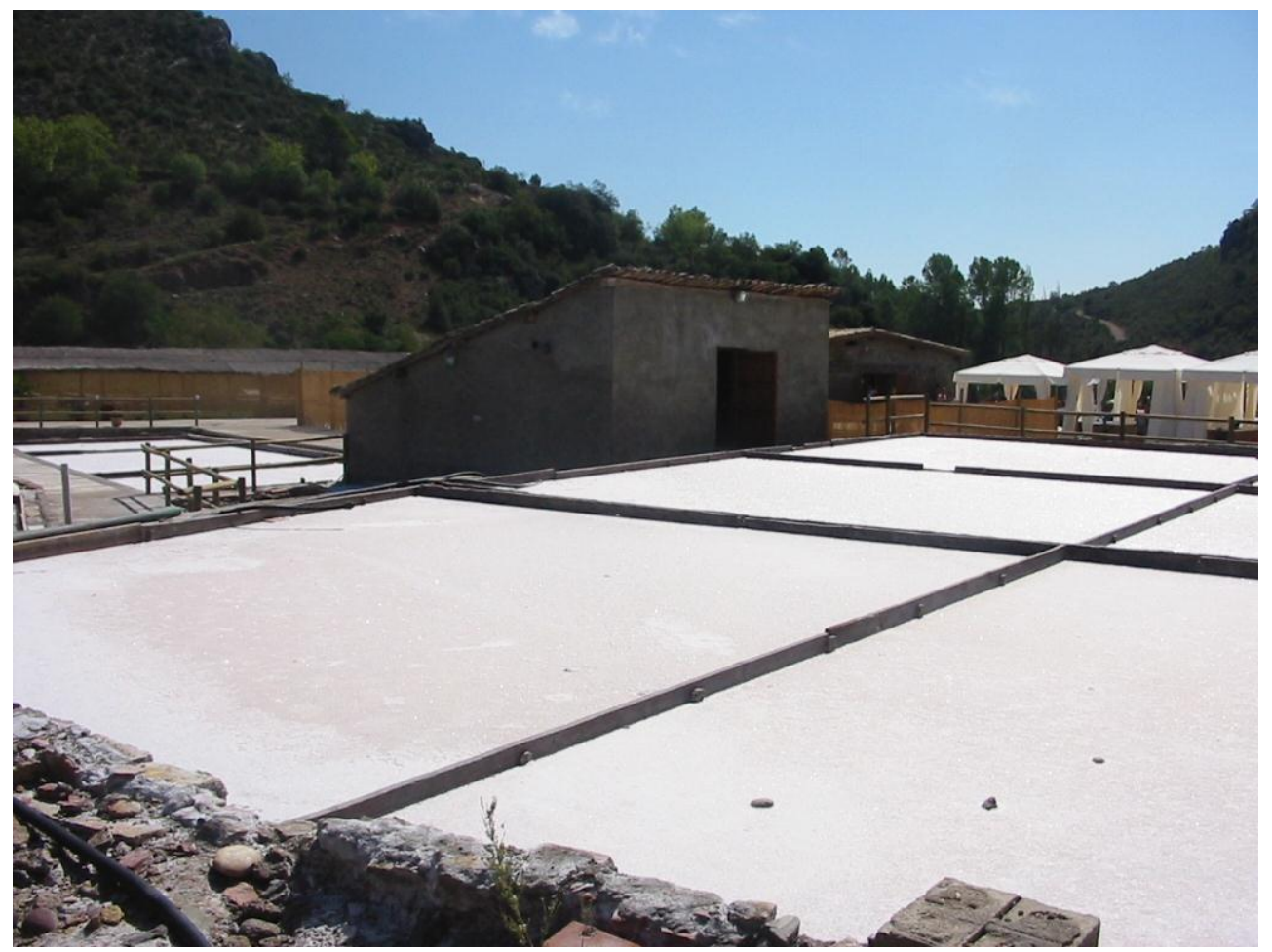

Aprovechamiento actual de la sal 
En la actualidad, en estas salinas se vuelve a obtener sal, utilizándose también como baños de talasoterapia. Sin embargo, ahora estas salinas se conocen con el nombre de Salinas de la Rolda.

PARADA 2 - CONDICIONAL. SALINAS DE GUIBANO, (término municipal de Naval, comarca del Somontano). (Hoja 250).

Después de realizar la parada anterior, cabe ir hacía Naval, para luego continuar hacía Abizanda. Sin embargo, poco después de sobrepasar Naval, se encontrará un camino por la izquierda que conduce a las Salinas de Guibano. Éstas se hallan a menos de $1 \mathrm{Km}$ del pueblo. Y a $2 \mathrm{Km}$ de la parada anterior. Aquí haremos otra parada.

En este recorrido hemos ido encontrando afloramientos de los materiales triásicos del Keuper, fundamentalmente con arcillas y con yesos. Estos, como en el caso anterior, son también los que afloran en el lugar de la parada.

$Y$ como en el caso anterior, se han aprovechado (en unas eras), las aguas saladas, ricas en HALITA, que han circulado a través de los materiales del Keuper.

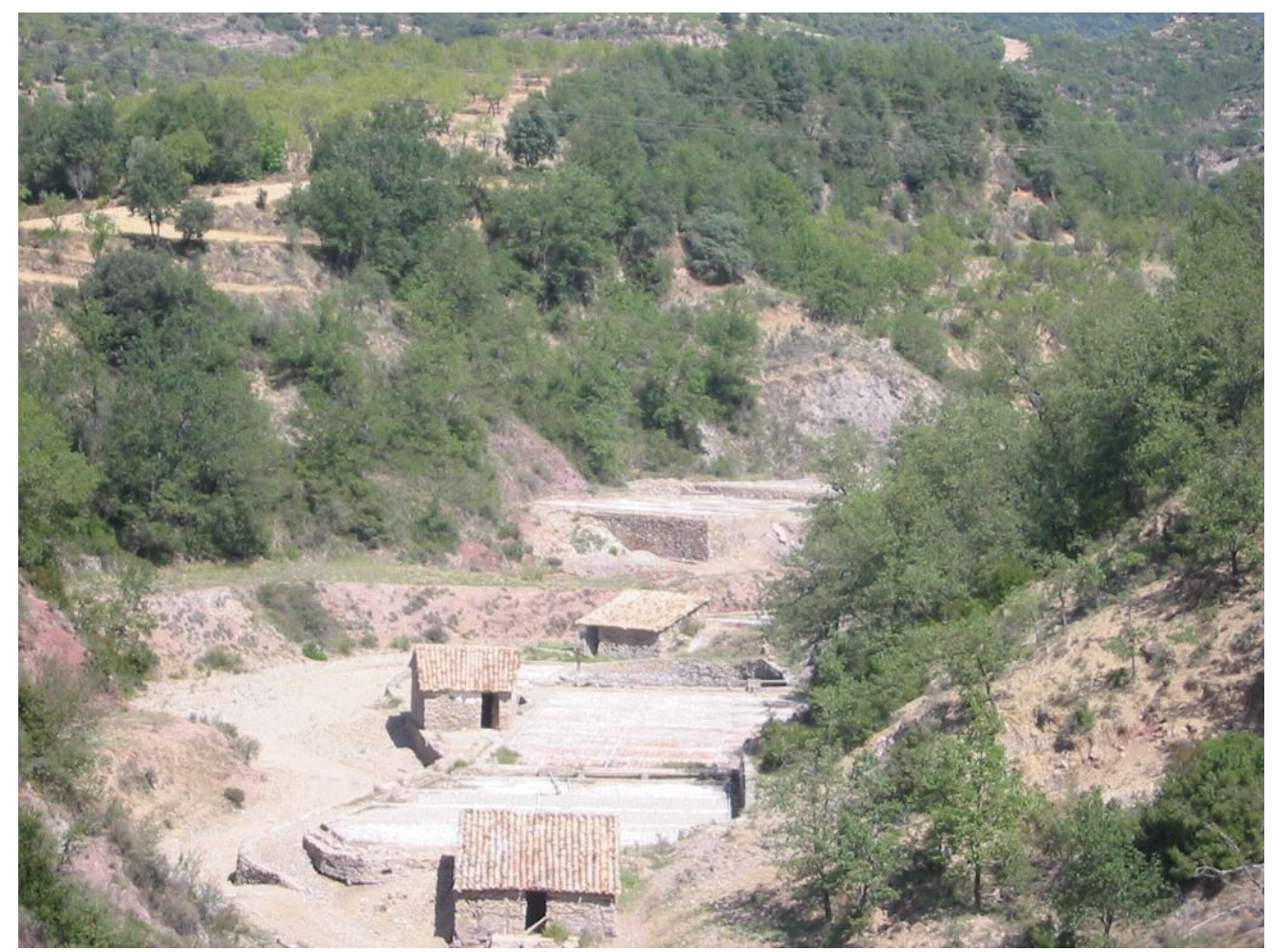

Un aspecto de las eras

PARADA 3. ENTRADA A ABIZANDA, (término municipal de Abizanda, comarca del Sobrarbe). (Hoja 250).

Desde la parada anterior, es necesario retornar a las inmediaciones de Naval, con la finalidad de seguir por la carretera que conduce a Abizanda, pasando ahora de la comarca del Somontano a la del Sobrarbe. Al llegar al cruce de esta última población, nos 
convendrá tomarlo para ir hacía el pueblo. Casi a la entrada de él, efectuaremos una nueva parada, a unos $12 \mathrm{Km}$ de la anterior, tras pasar el Puerto de Pino.

Este recorrido lo habremos efectuado entre afloramientos mesozoicos (fundamentalmente del Triásico y del Cretácico) de las Sierras Marginales del Surpirineo Central, en donde nos encontramos. A menudo, estos materiales se hallan recubiertos por depósitos cuaternarios de derrubios de pendiente.

Desde este lugar se goza de un incomparable punto de observación del imponente Anticlinal de Santa Bárbara, situado al Norte de donde ahora estamos. Se halla en las cercanías de Samitier, Palo y Mediano.

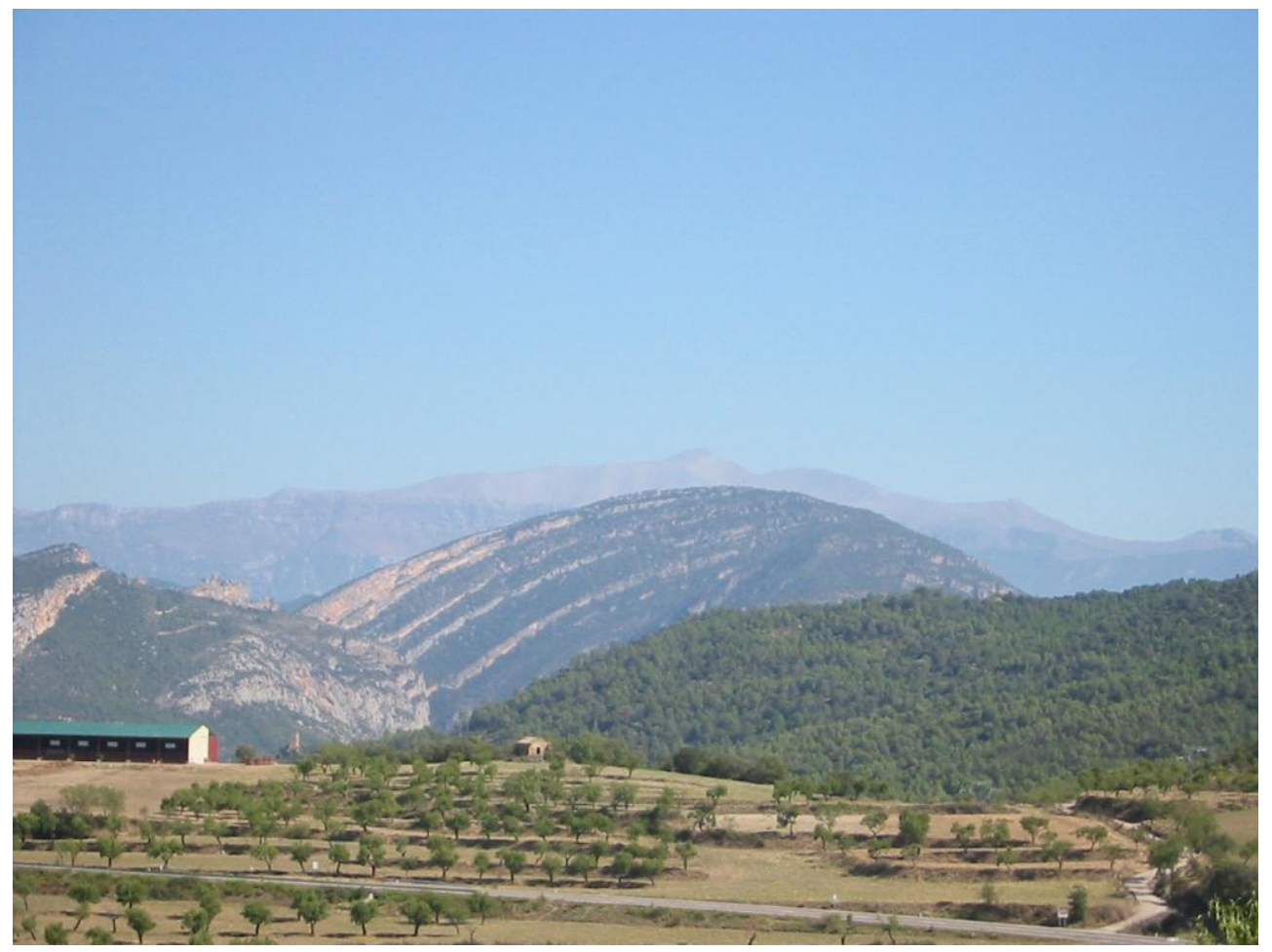

Un aspecto del Anticlinal de Santa Bárbara, desde Abizanda

PARADA 4. CONGOSTO DEL BARRANCO DEL RÍO, (término municipal de Abizanda, comarca del Sobrarbe). (Hoja 250).

Tras realizar la parada anterior, conviene hacer un breve recorrido, con la finalidad de llegar a la carretera autonómica que comunica Barbastro con l'Ainsa. Al encontrarla, será necesario continuar por ella hacía el Sur, efectuando una hijuela. A menos de $2 \mathrm{Km}$ del cruce, efectuaremos una nueva parada.

En este recorrido, habremos encontrado afloramientos de los materiales mesozoicos, fundamentalmente carbonatados, del Cretácico. Estos son los materiales que aparecen en el lugar de la parada. Estos materiales, como los anteriormente vistos, pertenecen a las Sierras Marginales del Surpirineo Central, en donde nos seguimos encontrando en este lugar. 
Aquí, estos materiales forman un cañón por el que circula el Barranco del Río, procedente de Abizanda, camino del río Cinca del que es afluente. Una perspectiva de este cañón es la siguiente.

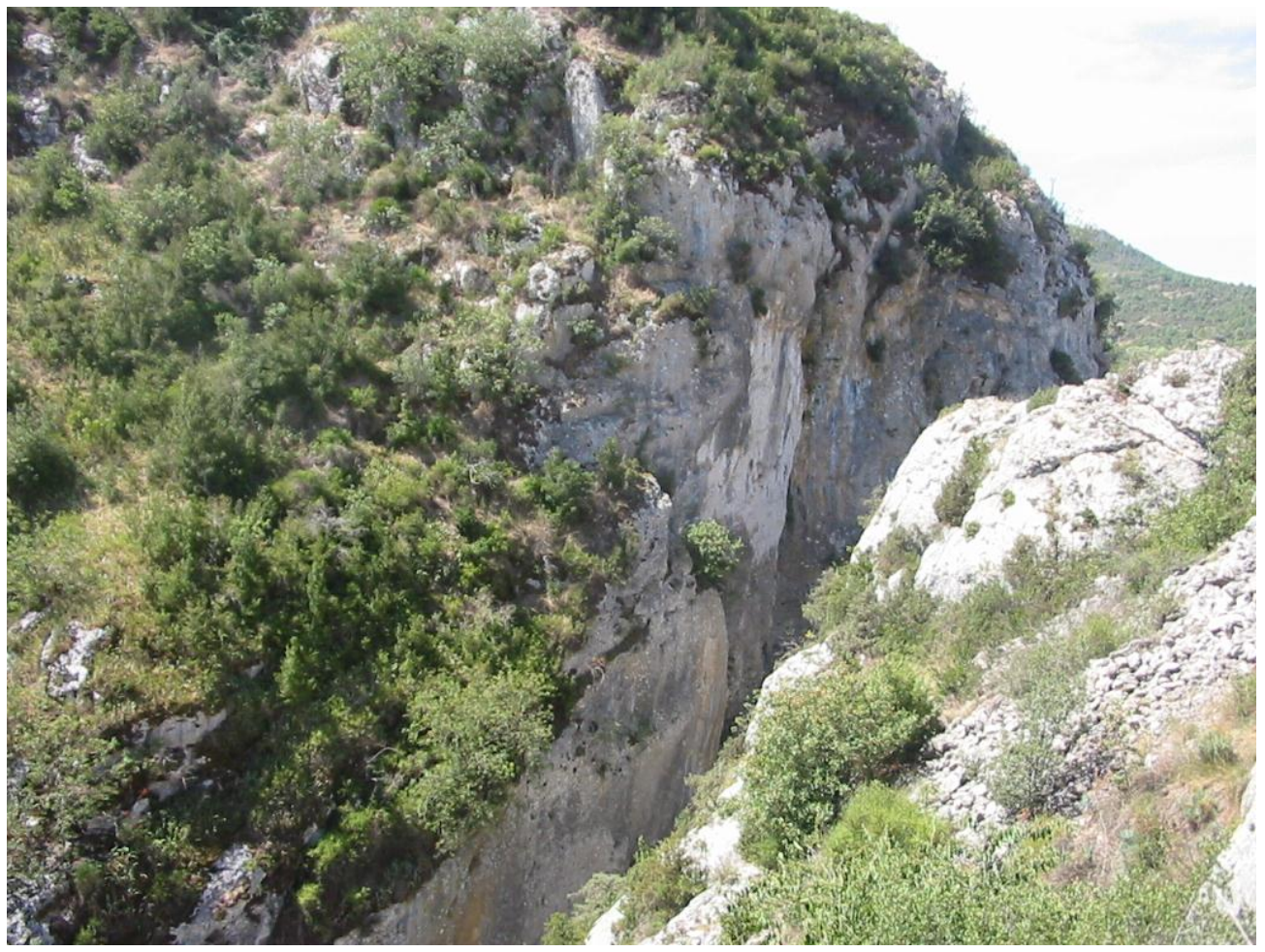

El congosto del Barranco del río

PARADA 5. EL ENTREMON, (términos municipales de la Fueva y de Palo, comarca del Sobrarbe). (Full 250).

Tras realizar la parada anterior, conviene retornar hacía las inmediaciones de Abizanda, para continuar luego por la carretera que conduce hacía l'Ainsa. Por esta carretera pronto pasaremos por las inmediaciones del pueblo de Escanilla. Posteriormente (por la izquierda) el camino - carretera que conduce a Lamata y a Javierre.

Poco después llegaremos al Mesón de Ligüerri. Ahí nos convendrá seguir (haciendo una hijuela) por la carretera que conduce a Panillo y a Tierrantona. A través de esta carretera llegaremos al puente sobre el río Cinca. Ahí efectuaremos una nueva parada, a unos $10 \mathrm{Km}$ de la anterior.

En este recorrido habremos ido encontrando afloramientos de los materiales mesozoicos citados en las paradas anteriores. Como en los casos anteriores, estos materiales pertenecen a las Sierras Marginales del Surpirineo Central, en donde nos seguimos encontrando en este lugar.

Por otra parte, desde este lugar, mirando hacia el Norte, puede observarse un estrecho (el Entremon), por el cual el río Cinca atraviesa los materiales carbonatados 
mesozoicos, que forman aquí parte del flanco occidental del Anticlinal de Santa Bárbara, que ya hemos visto en la segunda parada, desde la población de Abizanda.

Una instantánea correspondiente a este estrecho (que forma parte del Inventario del Patrimonio Geológico del Sobrarbe), es el siguiente.

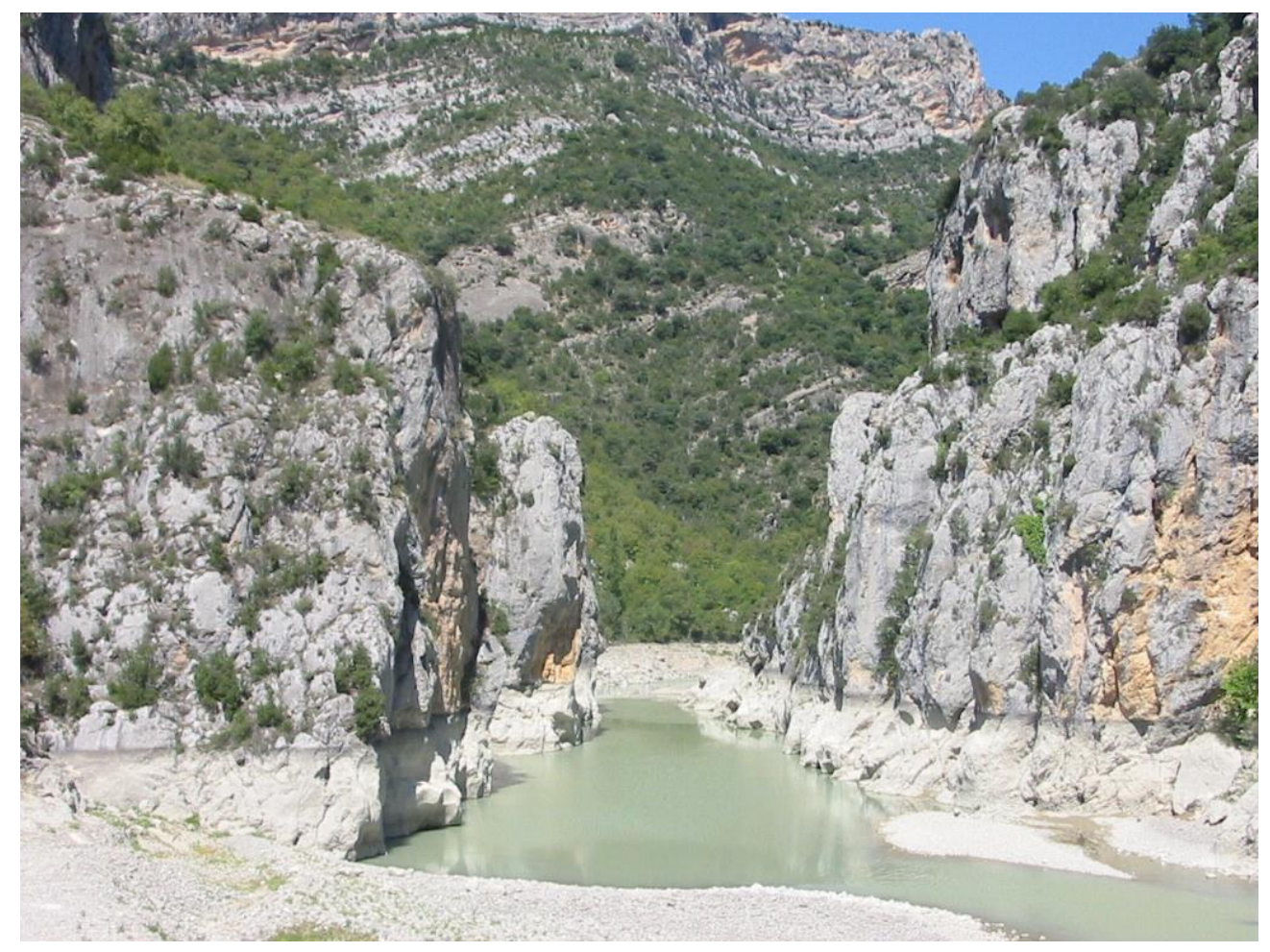

Un aspecto del Entremon.

Tras él se pueden observar los materiales del flanco occidental del Anticlinal de Santa Bárbara

PARADA 6. EL TEJAR DE PARDINA, (la Pardina, término municipal de l'Ainsa -Sobrarbe, comarca del Sobrarbe). (Full 212).

Tras realizar la parada anterior, conviene retornar hacía el Mesón de Ligüerri, para seguir luego por la carretera autonómica que conduce hacía l’Ainsa. Por esta carretera pronto llegaremos a Mediano (en realidad al Barrio Nuevo de Mediano), tras pasar antes por las inmediaciones del pueblo de Samitier. Desde este lugar, desde Mediano, conviene tomar la carretera que conduce a la Pardina. Al llegar ahí, efectuaremos una nueva parada, tras recorrer unos $14 \mathrm{Km}$ desde la parada anterior.

En este recorrido habremos encontrado afloramientos de los materiales mesozoicos citados anteriormente. Así habremos visto afloramientos de calcolutitas y de calcoarenitas mesozoicas. En algunos lugares, entre Mediano y la Pardina, se encuentran antiguas explotaciones de estos materiales, para ser dedicados a la construcción

Al llegar a la Pardina, se puede ver una interesante tejera. Ésta se halla en el pueblo. Se halla en buen estado de conservación, aunque ha sido recientemente habilitada 
como vivienda para un particular. Aun así, es un excelente valor de nuestro Patrimonio Minero, que merece ser conservado.

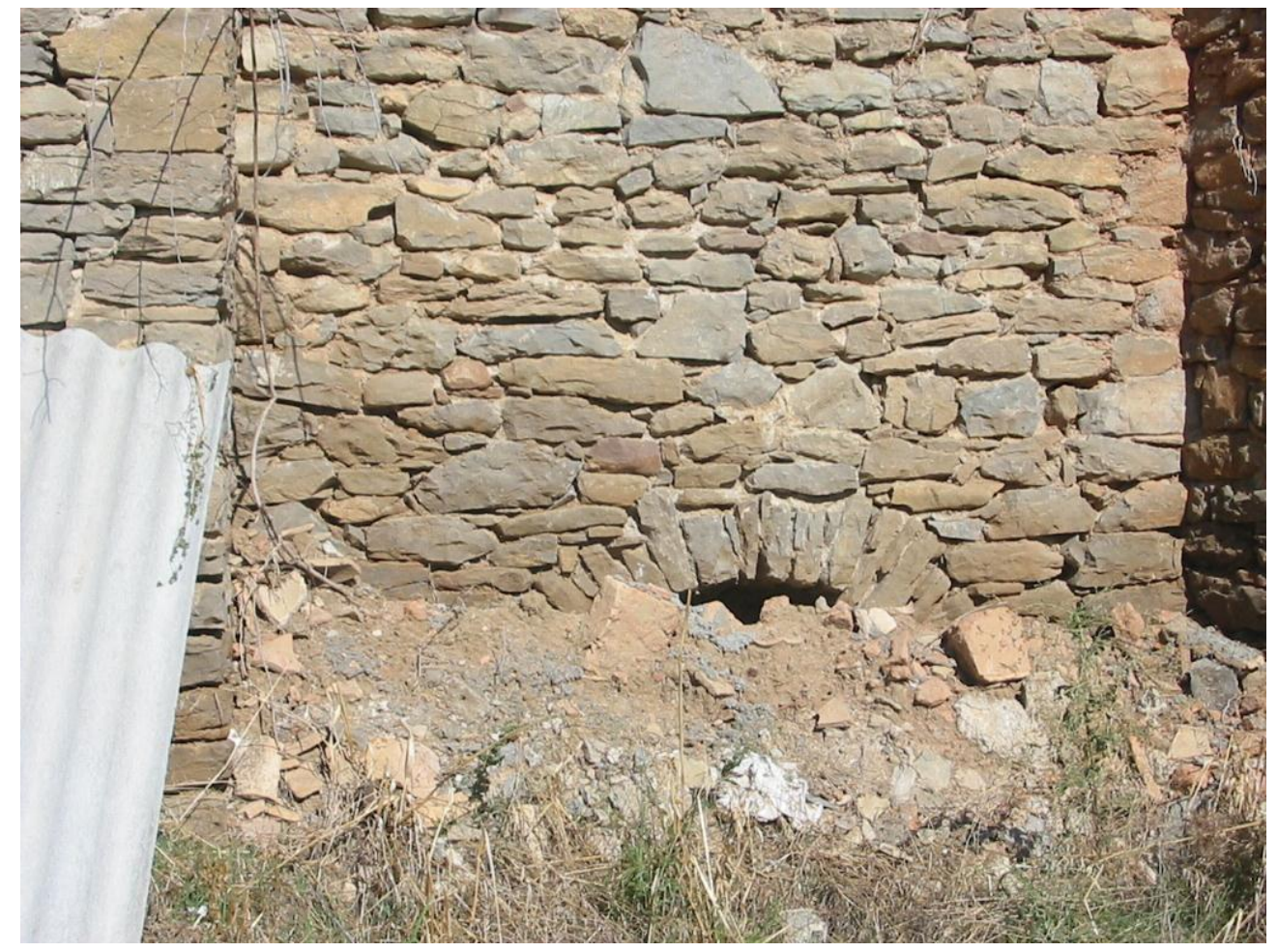

Un aspecto de la tejera, con la boca del horno

PARADA 7. CENTRO DE INTERPRETACIÓN DEL GEOPARQUE DEL SOBRARBE, (l'Ainsa, término municipal d'Ainsa - Sobrarbe, comarca del Sobrarbe). (Hoja 211).

Tras efectuar la parada anterior, cabe retornar hacía las inmediaciones de Mediano. Luego, desde ahí nos conviene seguir hacía el Norte, pasando por las inmediaciones de Camporrotuno, de Coscojuela de Sobrarbe y por Morillo de Tous. Finalmente llegaremos a l'Ainsa. Ahí efectuaremos una nueva parada, la última de este recorrido, a unos $15 \mathrm{Km}$ de la anterior. Esta parada la efectuaremos en el Castillo de l'Ainsa, en donde se encuentra el Centro de Interpretación del Geoparque del Sobarbe.

En este recorrido, como en los casos anteriores, encontraremos afloramientos de los materiales mesozoicos. Así, cabe destacar los importantes afloramientos de calcolutitas que habremos encontrado cerca de Coscojuela de Sobrarbe.

Por lo que concierne al lugar de la parada, cabe decir que ahí se halla una interesante exposición dedicada a la geología de esta comarca, que recomendamos visitar. Este lugar forma parte del Geoparque del Sobrarbe, que recomendamos visitar. Este Geoparque es uno de los cuatro que forman parte del territorio estatal.

\section{EN ESTE LUGAR FINALIZA EL ITINERARIO}




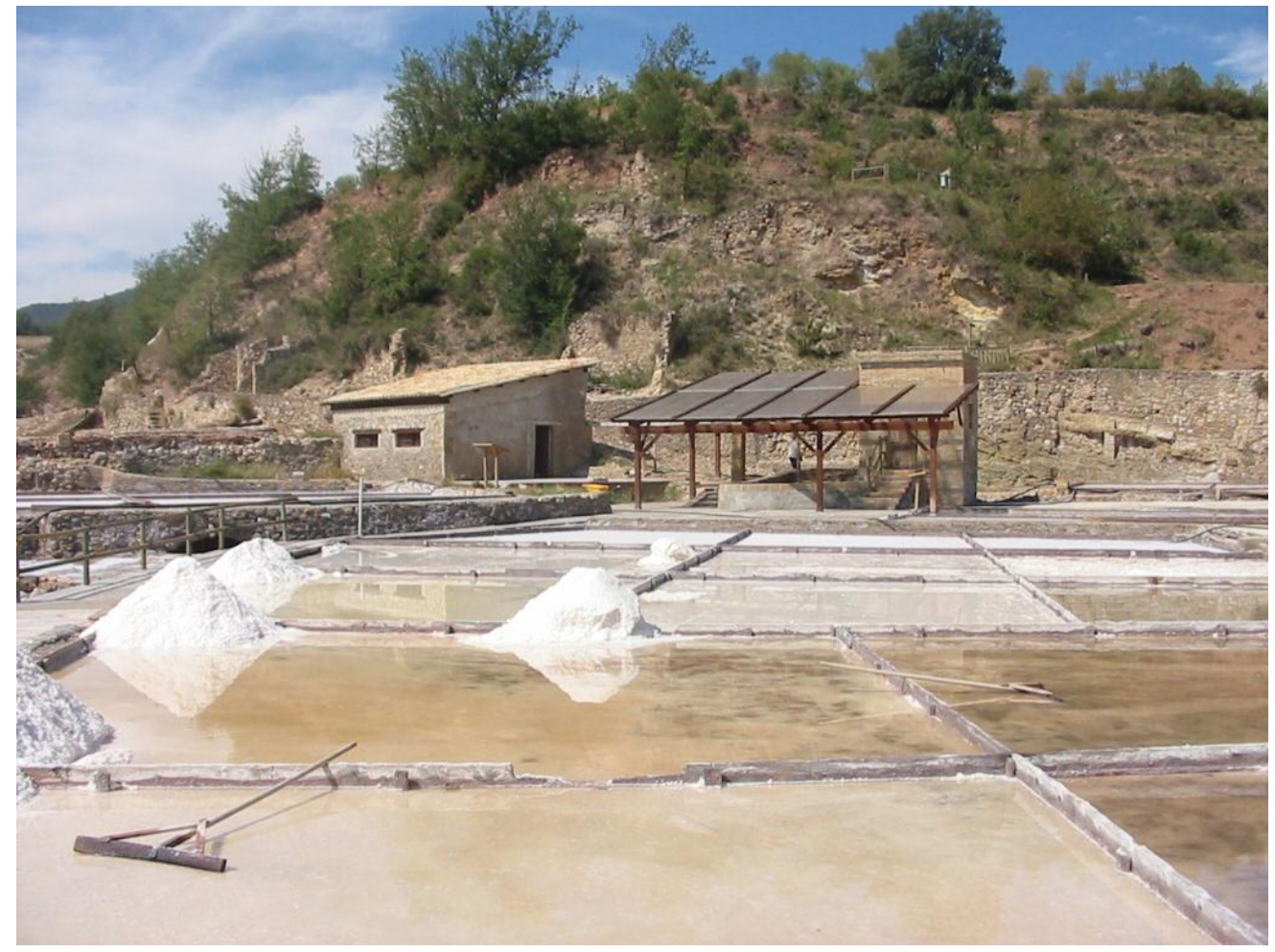

DETALLE DE UNA DE LAS SALINAS DE NAVAL (SOMONTANO)

\section{BIBLIOGRAFÍA}

CALVO, M. et altri (1988). - Minerales de Aragón, Colección Temas Geológicos, 207 Pág. Zaragoza

GOBIERNO DE ARAGÓN (2001).- Puntos de Interés Geológico de Aragón. Consejería de Medio Ambiente del Gobierno de Aragón. Zaragoza

IGME (1972).- Mapa Geológico de España a escala 1:200.000 (Síntesis de la cartografía existente). Hoja y Memoria na 23 (Huesca). Inst. Geol. Min. España

IGME (1973).- Mapa Metalogenético de España a escala 1:200.000. Hoja y Memoria ${ }^{a}{ }^{a}$. 23 (Huesca). Inst. Geol. Min. España

IGME (1975).- Mapa de Rocas Industriales de España a escala 1:200.000. Hoja y Memoria $n^{a}$. 23 (Huesca). Inst. Geol. Min. España

MAESTRE, A. (1845).- Descripción geognóstica del Distrito Minero de Cataluña y Aragón. Anales de Minas, t. III. Madrid 
MATA - PERELLÓ, J.; (1987).- Introducción al conocimiento de las mineralizaciones aragonesas. Mineralogistes de Catalunya, t.III, pp. 258-265. Barcelona

MATA - PERELLÓ, J.M. (1992).- Inventario Mineralógico de la comarca del Sobrarbe. Rodeno, 13. 42 Pág. Manresa

MATA - PERELLÓ, J.M. (1998).- Recorregut de recerca geológica i mineralógica per les comarques del Semontano i del Sobrarbe: des de Barbastro a Ceresa, per Naval i Laspuña. Pub. Museu de Geologia UPC, 10 pag. Manresa

MATA - PERELLÓ, J.M. (2005).- Recorregut de recerca geológica i mineralógica per les comarques del Semontano i del Sobrarbe: des de Barbastro a Ceresa, per Naval, Laspuña i l'Ainsa. Pub. Museu de Geologia UPC, 10 pag. Manresa

MATA - PERELLÓ, J.M. (2007).- Recorregut de recerca geológica i mineralógica per les comarques del Semontano i del Sobrarbe: des de Barbastro a Ceresa, per Naval, Laspuña i l'Ainsa. Pub. Museu de Geologia UPC, 10 pag. Manresa

MATA-PERELLÓ, J.M. y SANZ-BALAGUË, J. (1992).- Guía de Identificación de Minerales, adaptada fundamentalmente a la Península Ibérica. Edic. Parcir, 243 pag. Manresa

PRAMES (2005).- Sobrarbe. Colección RUTASCAL por Aragón. Prames, Gobierno de Aragón. 119 pag. Zaragoza. 